\title{
Transcriptome Profiling in Hybrid Poplar Following Interactions with Melampsora Rust Fungi
}

\author{
Aïda Azaiez, Brian Boyle, Valérie Levée, and Armand Séguin \\ Natural Resources Canada, Canadian Forest Service, Laurentian Forestry Centre, 1055 du P.E.P.S., P.O. Box 10380, \\ Stn. Sainte-Foy, Quebec, QC G1V 4C7, Canada
}

Submitted 19 June 2008. Accepted 13 October 2008.

In natural conditions, plants are subjected to a combination of biotic stresses and often have to cope with simultaneous pathogen infections. In this report, we aim to understand the global transcriptional response of hybrid poplar NM6 (Populus nigra $\times$ P. maximowiczii) to infection by two biotrophic Melampsora fungi, Melampsora larici-populina and $M$. medusae f. sp. deltoidae. These pathogens triggered different responses after inoculation of poplar leaves. Transcript profiling using the GeneChip Poplar Genome Array revealed a total of $\mathbf{4 1 6}$ differentially expressed transcripts whose expression level was $\geq$ twofold relative to controls. Interestingly, approximately half of the differentially expressed genes in infected leaves showed altered expression following interaction with either of the Melampsora spp. We also infected poplar leaves simultaneously with both Melampsora spp. to investigate potential interaction between the responses to the individual pathogens during a mixed infection. For this mixed inoculation, the number of differentially expressed transcripts increased to 648 and our analysis showed that infection with both fungi also induced a common set of genes. The genes induced after Melampsora spp. infection were mainly related to primary and secondary metabolic processes, cell-wall reinforcement and lignification, defense and stress-related mechanisms, and signal perception and transduction.

Additional keywords: compatible interaction, necrosis, quantitative resistance.

Plants are attacked by a diverse range of pests, including microbial pathogens. They consequently have developed countermeasures to resist most potential invaders. In this respect, several biochemical and physiological events occur in plant cells in response to pathogen recognition. The primary immune response is initiated after recognition of microbial-associated molecular patterns (MAMPs) by cell surface receptors and subsequent activation of regulatory proteins, protein kinases, and transcription factors (Bittel and Robatzek 2007). These signaling cascades usually lead to upregulation of defense-related genes. Plant innate immunity can also include the hypersensitive response (HR), which results in tissue necrosis and localized cell

Corresponding author: A. Séguin; Telephone: +1 418-648-5832; Fax: +1 418-648-5849; E-mail: armand.seguin@NRCan.gc.ca

Current address of B. Boyle: Arborea Project, Centre d'Études de la Forêt, Pavillon Charles-Eugène Marchand, Université Laval, 1030 Avenue de la Médecine, Quebec, QC G1V 0A6, Canada.

* The $e$-Xtra logo stands for "electronic extra" and indicates that three supplemental tables and one supplemental figure are published online. death at the site of infection, as well as reinforcement of cell walls surrounding the infected region by deposition of lignin and related wall-bound phenolics (Eulgem 2005; Garcia-Brugger et al. 2006). Our knowledge of defense-associated gene expression is extended by novel large-scale profiling technologies, which make it possible to identify new defensive functions or mechanisms (Ramonell and Somerville 2002; Tao et al. 2003; Wise et al. 2007). For instance, it has been previously shown that up to 25\% of all Arabidopsis genes alter their transcript levels in response to pathogen infection (Tao et al. 2003).

Poplars are an important tool for woody plant genomics research. The complete sequencing of the Populus trichocarpa Nisqually-1 genome (Brunner et al. 2004; Tuskan et al. 2006) has enabled studies to decipher a variety of processes unique to tree and woody plant biology. Due to its perennial trait, Populus spp. must defend themselves against herbivores and pathogens year after year. Understanding the defense strategies used by perennial plants like trees may reveal specific molecular processes that will complement our current knowledge of defense mechanisms, which relies mostly on studies of herbaceous, annual plants (Jones and Dangl 2006).

Transcriptome analyses should shed some light on the genes that are associated with resistance as well as those expressed during disease development. Transcriptome investigations have studied poplar defense responses to biotic stresses such as viral infection and herbivore attack using microarray technology (Major and Constabel 2006; Ralph et al. 2006; Smith et al. 2004). More recently, two studies examined the transcriptional response of hybrid poplar to biotrophic rust infection during compatible (Miranda et al. 2007; Rinaldi et al. 2007) and incompatible interactions (Rinaldi et al. 2007).

Biotrophic basidiomycetes of the genus Melampsora are among the major pathogens of Populus spp. found worldwide and the genetics of this interaction have been studied for at least two decades (Prakash and Heather 1986). However, biotrophic interactions remain poorly documented, principally because biotrophs cannot be maintained on culture media due to their special relationship with the host. Biotrophic pathogens develop sophisticated infection structures called haustoria within infected cells and keep host cells alive to acquire nutrients by minimizing tissue damage (Voegele and Mendgen 2003). A few reports have recently analyzed crop and model plant transcript profiles after biotrophic infection. For example, plantpowdery mildew interactions were studied on a large scale for tomato (Li et al. 2006) and barley (Caldo et al. 2006), and rust interaction was analyzed using the whole-genome Affymetrix GeneChip microarray for soybean (Panthee et al. 2007). More recently, the transcriptome was monitored for the powdery mildew-grapevine interaction using the Vitis spp. GeneChip (Fung et al. 2008). 
Melampsora leaf rust causes severe damage, including decreased photosynthesis efficiency, early defoliation, and reduced yields (Gérard et al. 2006; Newcombe 1996). Melampsora larici-populina and Melampsora medusae f. sp. deltoidae are two important species of the genus Melampsora found in poplar plantations and are usually identified as the European and North American species, respectively (Newcombe 1996). M. larici-populina infection results in a compatible interaction on poplar clone NM6 (P. nigra $\times P$. maximowiczii), with the formation of many uredinias on the leaf epidermis, and, conversely, M. medusae f. sp. deltoidae infection leads to quantitative resistance on clone NM6, with macroscopic necroses and only partial pathogen growth. In this study, we examine the global transcriptional response of hybrid poplar NM6 to infection by two biotrophic Melampsora fungi, M. larici-populina and $M$. medusae f. sp. deltoidae, in separate and mixed infections using high-density GeneChip Poplar Genome Arrays.

To our knowledge, this is one of only a few transcript profiling analyses of a plant defense response induced by mixed infection with two pathogens simultaneously. In the mixed $M$. larici-populina and $M$. medusae f. sp. deltoidae infection, the defense response induced by $M$. medusae f. sp. deltoidae, which blocks pathogen progress, did not prevent $M$. larici-populina growth when inoculated simultaneously on the same NM6 leaf disk. Lack of interference between the two pathogens in the simultaneous infection prompted us to explore the underlying

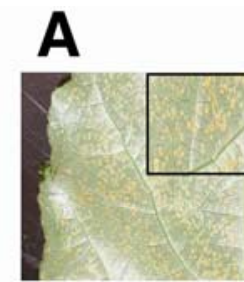

Mlp

B

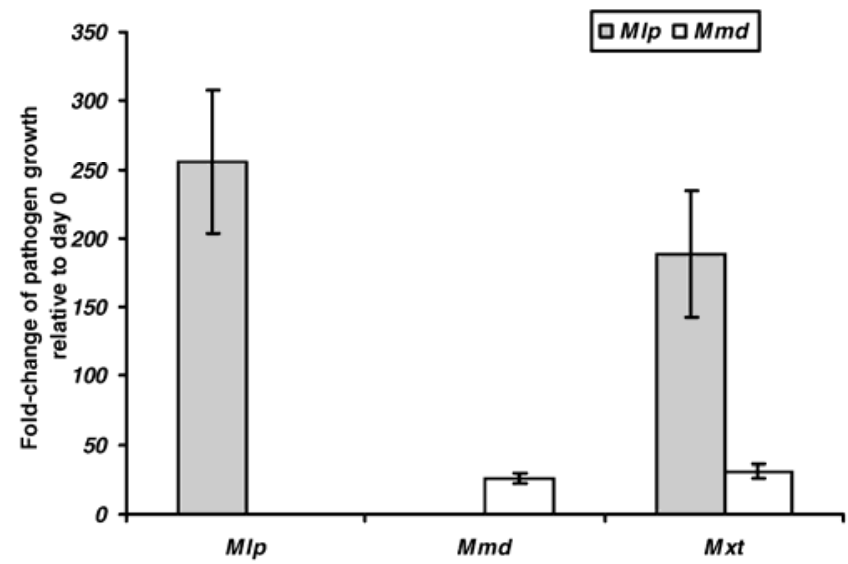

Fig. 1. Contrasting responses among Melampsora spp. interactions with poplar clone NM6. A, Uredinia production is observed during interaction between clone NM6 and Melampsora larici-populina (Mlp) (left panel). Macroscopic necrotic lesions characteristic of defense-related cell death are observed in the interaction between clone NM6 and M. medusae f. sp. deltoidae $(\mathrm{Mmd})$ (middle panel). In the mixed infection $(\mathrm{Mxt}=\mathrm{Mlp}+$ $M m d$ ), a combination of the two phenotypes described above is observed (uredinias and necrosis) (right panel). Photos were taken at 10 days postinoculation (dpi) and leaf abaxial side is shown. B, Pathogen growth determined by quantitative polymerase chain reaction of the relative increase in pathogen DNA mass at 6 dpi compared with mock-inoculated samples. Analyses were done in triplicate and each replication was repeated two times. Bars represent standard deviations. molecular mechanisms in more detail. We show that infection by one Melampsora sp. does not impact the transcriptional response induced by another on the same leaf, which is consistent with the absence of interference in pathogen growth.

\section{RESULTS}

\section{Contrasting responses}

in Melampsora spp. interactions with poplar clone NM6.

On poplar clone NM6, M. larici-populina produced orange pustules called uredinias (Fig. 1A, left panel), which fully matured 10 days postinfection (dpi). No visible symptoms of a defense reaction were observed for this interaction. On the other hand, infection of clone NM6 by M. medusae f. sp. deltoidae resulted in macroscopic necrotic lesions, limiting pathogen growth (Fig. 1A, middle panel). When both pathogens were inoculated simultaneously (mixed or combined infection), a combination of uredinias and necroses were observed at $10 \mathrm{dpi}$ (Fig. 1A, right panel). Apparently, growth of one pathogen was unaffected by the presence of the other in the mixed infection
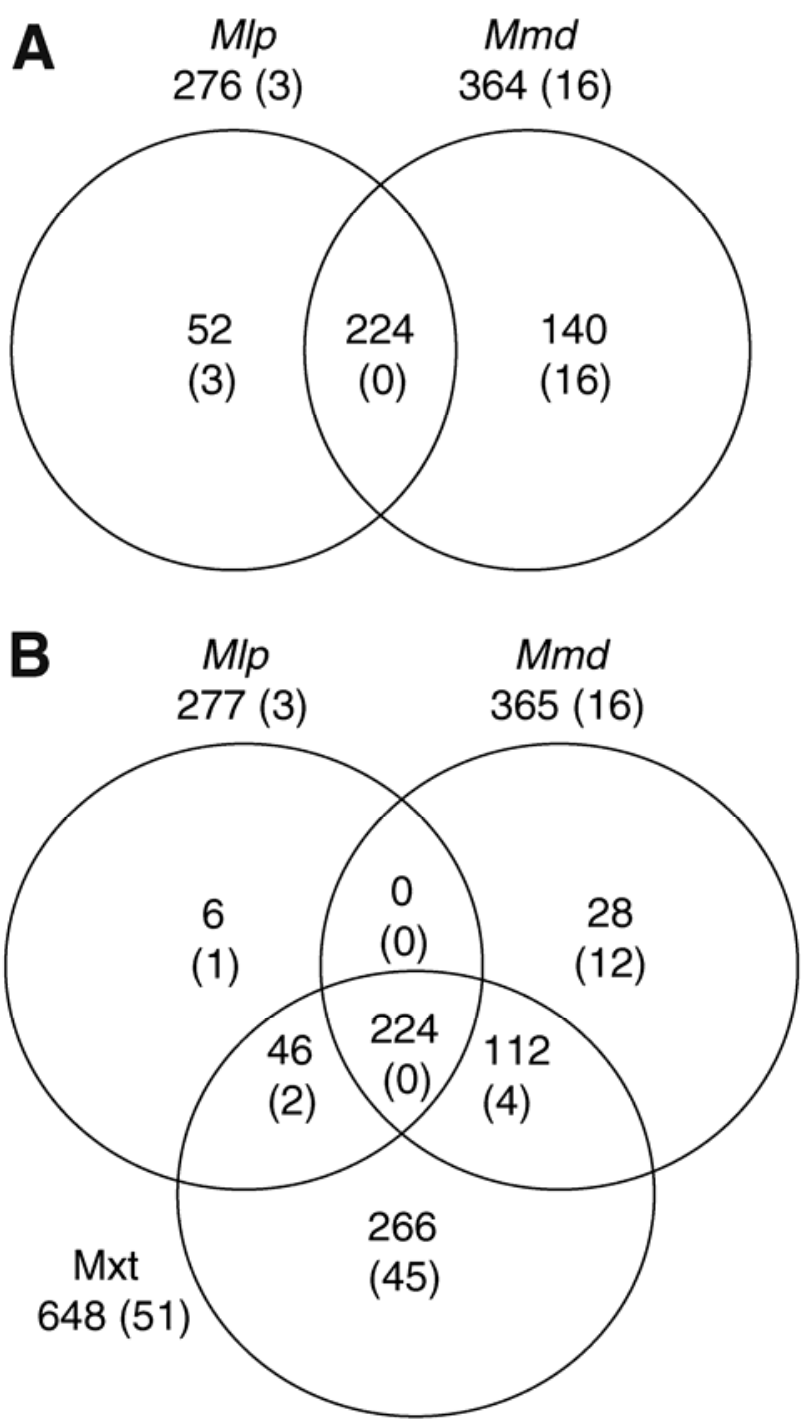

Fig. 2. Venn diagrams of rust-regulated genes in response to $\mathbf{A}$, Melampsora larici-populina (Mlp) and M. medusae f. sp. deltoidae (Mmd) and B, Mlp, $M m d$, and the mixed infection (Mxt). Venn diagrams show distinct and overlapping sets of differentially regulated gene (subsets of downregulated genes are in parentheses) transcripts in response to each treatment. All transcripts identified were differentially regulated by rust infection (fold change $\geq 2$ and $P$ value $\leq 0.01)$ relative to control samples (mock inoculated). 
because we observed a combination of both infection phenotypes characteristic of each pathogen. We measured pathogen growth 6 days after infection by quantitative polymerase chain reaction (qPCR), which is an important turning point in the outcome of the interaction (Boyle et al. 2005). Unpublished data from our laboratory also demonstrated that quantitative resistance is established at approximately 5 dpi, when key defense genes are induced. In the M. larici-populina-NM6 compatible interaction, pathogen DNA mass increased 250-fold after 6 days of growth (ratio of 6 dpi to day 0). However, pathogen growth was restricted to 25 -fold in the M. medusae f. sp. deltoidae-NM6 interaction at 6 dpi. Consequently, the overall growth of $M$. larici-populina was 10 times more than M. medusae f. sp. deltoidae on clone NM6. When both pathogens were infected simultaneously, a slight but not significant decrease in pathogen growth was measured for M. larici-populina, whereas no change in $M$. medusae f. sp. deltoidae development was observed (Fig. 1B).

\section{Global gene regulation in response to different interactions with Melampsora spp.}

In order to identify transcriptional changes associated with rust infection, we performed expression-profiling experiments using the Affymetrix GeneChip Poplar Genome Array. We applied the commonly used threshold of a twofold difference in gene expression (Clarke and Zhu 2006) on probe sets with a $P$ value $\leq 0.01$ following significance analysis of microarray (SAM) (discussed below) between infected and noninfected plants, which identified 416 genes that were differentially expressed after $M$. larici-populina or $M$. medusae f. sp. deltoidae infections. The Venn diagram in Figure 2A shows distinct responses in M. larici-populina- and M. medusae f. sp. deltoidaeinfected poplar leaves. We identified 364 (348 up- and 16 downregulated) and 276 (273 up- and 3 downregulated) poplar probe sets that accumulated differentially during quantitative resistance to $M$. medusae f. sp. deltoidae and the susceptible reaction to $M$. larici-populina, respectively. Interestingly, we observed a

Table 1. Expression level, assessed by GeneChip Poplar Genome Array, of selected rust differentially expressed genes (cutoff of twofold $\log _{2}$ ) categorized according to their biological groups

\begin{tabular}{|c|c|c|c|c|c|c|}
\hline \multirow[b]{2}{*}{ Affymetrix probe set ID } & \multirow[b]{2}{*}{ Protein ID } & \multirow[b]{2}{*}{ TAIR (BlastX) } & \multirow[b]{2}{*}{ Putative function $^{b}$} & \multicolumn{3}{|c|}{ Fold changes $^{a}$} \\
\hline & & & & Mlp & Mmd & Mix \\
\hline \multicolumn{7}{|l|}{ Cell wall modification } \\
\hline PtpAffx.207811.1.S1_at & 820457 & AT1G65610.1 & Endo-1,4- $\beta$-glucanase, putative / cellulase, putative & 1.90 & 3.21 & 4.02 \\
\hline PtpAffx.208729.1.S1_at & 821920 & AT4G24000.1 & ATCSLG2 (Cellulose synthase-like G2); transferase & 1.91 & 2.38 & 3.45 \\
\hline PtpAffx.11747.1.S1_at & 822767 & AT1G11580.1 & Pectin methylesterase (Sesbania rostrata) & 1.59 & 1.36 & 2.18 \\
\hline Ptp.3947.1.S1_s_at & 583623 & AT5G06860.1 & PGIP1 (polygalacturonase inhibiting protein 1); protein binding & 1.09 & 2.21 & 3.53 \\
\hline PtpAffx.1317.1.A1_at & 712150 & AT5G13870.1 & EXGT-A4 (endoxyloglucan transferase A4); hydrolase & 0.55 & 0.52 & 0.22 \\
\hline & & & & -1.82 & -1.92 & -4.56 \\
\hline \multicolumn{7}{|l|}{ Secondary metabolism } \\
\hline PtpAffx.89781.1.A1_at & 762155 & AT4G15550.1 & IAGLU (indole-3-acetate $\beta$-D-UDP-glycosyltransferase) & 5.56 & 5.23 & 16.47 \\
\hline Ptp.4154.1.S1_s_at & 553609 & AT5G07990.1 & $\begin{array}{l}\text { TT7 (transparent testa 7); flavonoid 3'-monooxygenase/oxygen } \\
\text { binding }\end{array}$ & 5.70 & 6.02 & 13.00 \\
\hline PtpAffx.16148.1.S1_at & 549334 & AT4G37980.1 & CAD (cinnamyl alcohol dehydrogenase) & 2.87 & 5.85 & 9.80 \\
\hline PtpAffx.17241.1.S1_at & 421493 & AT2G33590.1 & CCR (cinnamoyl-CoA reductase) & 2.14 & 2.61 & 3.11 \\
\hline PtpAffx.206981.1.S1_at & 802598 & AT1G75280.1 & Isoflavone reductase, putative (Vitis vinifera) & 1.64 & 5.15 & 5.71 \\
\hline PtpAffx.67810.1.A1_s_at & 835574 & AT5G05600.1 & Leucoanthocyanidin dioxygenase-like protein & 2.21 & 2.59 & 4.67 \\
\hline PtpAffx.203733.1.S1_s_at & 197012 & AT1G61680.1 & Terpene synthase/cyclase family protein & 2.65 & 2.22 & 4.23 \\
\hline PtpAffx.2272.1.S1_a_at & 770553 & AT2G37040.1 & PAL1 (phenylalanine ammonia-lyase 1) & 1.24 & 1.57 & 2.84 \\
\hline PtpAffx.5647.1.A1_at & 176985 & AT4G10500.1 & Flavanone 3-hydroxylase-like protein & 1.31 & 2.18 & 2.73 \\
\hline PtpAffx.55460.2.S1_a_at & 552360 & AT5G54160.1 & ATOMT1 ( $O$-methyltransferase 1$)$ & -1.64 & -1.69 & -3.45 \\
\hline \multicolumn{7}{|l|}{ Hormone metabolism $^{c}$} \\
\hline PtpAffx.202085.1.S1_at & 798910 & AT5G42650.1 & AOS (allene oxide synthase); hydro-lyase/oxygen binding & 1.84 & 2.98 & 3.22 \\
\hline Ptp.118.1.S1_at & 830388 & AT3G61510.1 & $\begin{array}{l}\text { ACS1 (ACC synthase 1); 1-aminocyclopropane-1-carboxylate } \\
\text { synthase }\end{array}$ & 1.26 & 1.85 & 3.13 \\
\hline PtpAffx.12244.1.A1_at & 430410 & AT3G25780.1 & AOC3 (allene oxide cyclase 3 ) & 1.69 & 2.00 & 2.70 \\
\hline PtpAffx.224263.1.S1_s_at & 756023 & AT2G26560.1 & PLP2 (phospholipase A 2A); nutrient reservoir & 1.38 & 2.02 & 2.71 \\
\hline Ptp.119.1.S1_at & 815069 & AT4G11280.1 & $\begin{array}{l}\text { ACS6 (1-aminocyclopropane-1-carboxilic acid (ACC) } \\
\text { (synthase 6) }\end{array}$ & 1.76 & 2.18 & 2.64 \\
\hline PtpAffx.71066.3.A1_a_at & 552732 & AT1G05010.1 & ACS (1-aminocyclopropane-1-carboxylate oxidase) & 1.72 & 1.54 & 2.55 \\
\hline PtpAffx.119413.1.A1_at & 828417 & AT1G72520.1 & Lipoxygenase, putative & 1.49 & 1.67 & 2.08 \\
\hline \multicolumn{7}{|l|}{ Signal perception $^{\mathrm{d}}$} \\
\hline PtpAffx.98587.2.S1_at & 259154 & AT5G39670.1 & Calcium-binding EF-hand family protein & 9.58 & 12.37 & 20.44 \\
\hline PtpAffx.214899.1.S1_ss_at & 178198 & AT1G79670.2 & RFO1 (resistance to Fusarium oxysporum 1) WALK2 & 4.10 & 8.57 & 16.15 \\
\hline PtpAffx.249.474.S1_at & 832275 & AT2G22240.1 & $\begin{array}{l}\text { Inositol-3-phosphate synthase isozyme } 2 / \text { myo-inositol-1- } \\
\text { phosp. synth. 2/IPS } 2\end{array}$ & 5.12 & 3.91 & 7.60 \\
\hline PtpAffx.217548.1.S1_s_at & 585070 & AT5G48380.1 & Putative systemin receptor SR160 (Oryza sativa) & 2.54 & 2.83 & 4.45 \\
\hline PtpAffx.67455.1.S1_at & 202273 & AT1G09970.1 & ATP binding/kinase/ protein serine/threonine kinase & 2.62 & 3.11 & 4.09 \\
\hline PtpAffx.213379.1.S1_at & 256178 & AT5G04870.1 & CPK1 (calcium-dependent protein kinase isoform AK1) & 2.32 & 2.43 & 3.37 \\
\hline PtpAffx.203336.1.S1_s_at & 554586 & AT3G47570.1 & Leucine-rich repeat transmembrane protein kinase, putative & 1.70 & 1.94 & 2.46 \\
\hline PtpAffx.221157.1.S1_at & 286831 & AT5G66850.1 & MAPKKK5 (mitogen-activated protein kinase kinase kinase 5) & 1.68 & 1.52 & 2.03 \\
\hline PtpAffx.3745.1.S1_at & 554949 & AT3G20820.1 & Leucine-rich repeat family protein & -1.72 & -2.56 & -7.14 \\
\hline
\end{tabular}

\footnotetext{
${ }^{\text {a }}$ Fold changes in induction or repression between control and each treatment-Melampsora larici-populina (Mlp), M. medusae f. sp. deltoidae (Mmd), and both combined (Mix) - are given; positive values represent upregulation and negative values represent downregulation. In the latter case, ratios $<1.0$ were inverted and multiplied by -1 to facilitate data reading. Expression data that fulfill fold change and significant $P$ values criteria are in shaded boxes.

${ }^{\mathrm{b}}$ Organisms if different from Arabidopsis thaliana.

${ }^{\mathrm{c}}$ Hormone metabolism and signaling.

d Signal perception and transduction.

${ }^{\mathrm{e}}$ Stress response and detoxification.
} 
high proportion (54\%) of transcripts common to $M$. laricipopulina and $M$. medusae f. sp. deltoidae infections (224 upregulated genes) despite the different outcome of the interactions. However, a large number of probe sets were differentially regulated (140) only in response to $M$. medusae f. sp. deltoidae infection. This observation most probably reflects the active defense response elicited after inoculation with the partially virulent $M$. medusae f. sp. deltoidae. A detailed analysis of the genes differentially expressed after $M$. medusae f. sp. deltoidae but not M. larici-populina infection confirmed that a large proportion was associated with defense and stress-related responses. A closer look at genes differentially regulated in response to $M$. larici-populina specifically did not reveal particular functions that may suggest control of host cellular processes by the colonizing fungus. However, seven genes (of a total of 49 genes differentially upregulated only after $M$. larici-populina infection) were involved in metabolic processes, particularly amino acid metabolism, and two genes were involved in cellular transport (e.g., nitrate transporter). Transcripts related to metabolic pathways represent the predominant functional class of genes in- duced after $M$. larici-populina infection. Overall, a very small proportion of genes exhibited a decrease in transcript abundance in response to rust infection, with only 19 identified probe sets. However, closer analysis of the transcriptional changes associated with Melampsora spp. infection revealed that more than 200 transcripts were downregulated below the twofold difference in gene expression and, thus, were not considered in our analysis (data not shown). Annotation of these probe sets revealed corresponding proteins related to general metabolic processes, as well as several of unknown function.

In order to identify potential interactions between the defense responses triggered by the two fungi on the host response, we inoculated poplar leaves with a mixture of M. larici-populina and M. medusae f. sp. deltoidae simultaneously. Analysis of transcript abundance after mixed inoculation (Fig. 2B) showed that 648 transcripts were differentially expressed between uninfected and rust-infected leaf tissues. These included 382 transcripts previously identified in response to separate $M$. larici-populina and $M$. medusae f. sp. deltoidae infections (Fig. 2A) and 266 novel transcripts exclusively regulated fol-

Table 1. (continued from preceding page)

\begin{tabular}{|c|c|c|c|c|c|c|}
\hline \multirow[b]{2}{*}{ Affymetrix probe set ID } & \multirow[b]{2}{*}{ Protein ID } & \multirow[b]{2}{*}{ TAIR (BlastX) } & \multirow[b]{2}{*}{ Putative function $^{\mathrm{b}}$} & \multicolumn{3}{|c|}{ Fold changes $^{a}$} \\
\hline & & & & Mlp & Mmd & Mix \\
\hline \multicolumn{7}{|l|}{ Transcription } \\
\hline PtpAffx.211278.1.S1_at & 571679 & AT3G56400.1 & $\begin{array}{l}\text { WRKY70 (WRKY DNA-binding protein 70); transcription } \\
\text { factor }\end{array}$ & 7.06 & 13.06 & 22.69 \\
\hline PtpAffx.205219.1.S1_at & 760201 & AT5G64810.1 & $\begin{array}{l}\text { WRKY51 (WRKY DNA-binding protein 51); transcription } \\
\text { factor }\end{array}$ & 8.98 & 15.06 & 21.74 \\
\hline PtpAffx.224226.1.S1_at & 816086 & AT2G31180.1 & $\begin{array}{l}\text { AtMYB14/Myb14at (myb domain protein 14); DNA } \\
\text { binding/transcription factor }\end{array}$ & 1.82 & 2.42 & 3.88 \\
\hline PtpAffx.1161.1.A1_at & 674314 & AT3G23240.1 & $\begin{array}{l}\text { ATERF1/ERF1 (ethylene response factor 1); DNA } \\
\text { binding/transcription factor }\end{array}$ & 1.25 & 2.67 & 3.02 \\
\hline PtpAffx.111515.1.S1_at & 822005 & AT1G69780.1 & $\begin{array}{l}\text { ATHB13 (homeobox protein 13); DNA binding/transcription } \\
\text { factor }\end{array}$ & -2.00 & -2.08 & -4.00 \\
\hline \multicolumn{7}{|l|}{ Stress, detoxification $^{\mathrm{e}}$} \\
\hline PtpAffx.43231.1.A1_a_at & 828962 & AT1G17180.1 & ATGSTU25 (glutathione $S$-transferase (class tau) 25) & 9.45 & 10.27 & 19.34 \\
\hline PtpAffx.3847.3.A1_at & 273420 & AT5G07990.1 & $\begin{array}{l}\text { Elicitor-inducible cytochrome P450; flavonoid 3'- } \\
\text { monooxygenase/oxygen binding }\end{array}$ & 7.30 & 7.06 & 14.76 \\
\hline PtpAffx.10106.1.S1_at & 555093 & AT5G06570.2 & HSR203J (Nicotiana tabacum) & 6.13 & 6.81 & 14.10 \\
\hline Ptp.4093.1.S1_at & 665543 & AT5G17540.1 & Transferase family protein; HSR201 (N. tabacum) & 4.71 & 5.47 & 10.71 \\
\hline PtpAffx.224160.1.S1_at & 181160 & AT2G21100.1 & $\begin{array}{l}\text { Disease resistance-responsive protein-related/dirigent protein- } \\
\text { related }\end{array}$ & 2.47 & 6.88 & 9.28 \\
\hline PtpAffx.201010.1.S1_at & 752663 & AT1G19250.1 & FMO1 (flavin-dependent monooxygenase 1) & 1.45 & 3.93 & 8.09 \\
\hline PtpAffx.86604.1.S1_at & 668104 & AT5G39580.1 & Peroxidase, putative & 5.68 & 1.39 & 6.69 \\
\hline PtpAffx.3203.5.S1_at & 818818 & AT4G24190.1 & Heat shock protein 90; SHD (SHEPHERD); ATP binding & 2.69 & 4.04 & 4.812 \\
\hline PtpAffx.55461.1.S1_at & 431737 & AT2G29420.1 & $\begin{array}{l}\text { Glutathione } S \text {-transferase GST } 18 \text { (Populus alba } \times P \text {. tremula } \\
\text { var. glandulosa] }\end{array}$ & 2.52 & 2.45 & 3.50 \\
\hline PtpAffx.28801.1.S1_at & 424354 & AT1G64060.1 & $\begin{array}{l}\text { ATRBOH F (respiratory burst oxidase protein F); NAD }(\mathrm{P}) \mathrm{H} \\
\text { oxidase }\end{array}$ & 2.19 & 2.15 & 3.15 \\
\hline PtpAffx.213517.1.S1_at & 576722 & AT3G50950.1 & Disease resistance protein (CC-NBS-LRR class), putative & 1.95 & 2.14 & 2.87 \\
\hline \multicolumn{7}{|l|}{ Defense-related proteins } \\
\hline PtpAffx.95130.1.A1_s_at & 819386 & AT2G18660.1 & $\begin{array}{l}\text { Expansin family protein (EXPR3); putative blight-associated } \\
\text { protein p12 precursor }\end{array}$ & 14.87 & 6.74 & 20.96 \\
\hline PtpAffx.32468.1.S1_at & 548498 & AT4G11650.1 & ATOSM34 (OSMOTIN 34); thaumatin-like protein & 5.27 & 7.75 & 15.07 \\
\hline PtpAffx.32356.3.S1_at & 652688 & AT3G57270.1 & $\begin{array}{l}\text { BG1 ( } \beta \text {-1,3-glucanase 1); hydrolase, hydrolyzing } O \text {-glycosyl } \\
\text { compounds }\end{array}$ & 6.46 & 9.13 & 16.48 \\
\hline PtpAffx.135403.1.S1_s_at & 648596 & AT2G16230.1 & Glycosyl hydrolase family 17 protein & 5.84 & 9.19 & 13.74 \\
\hline Ptp.999.1.A1_at & 710171 & AT2G13810.1 & ALD1 (AGD2-like defense response protein 1); transaminase & 2.27 & 6.75 & 9.29 \\
\hline PtpAffx.64603.1.S1_at & 233978 & AT5G24090.1 & Acidic endochitinase (CHIB1); pathogenesis-related protein & 3.39 & 2.85 & 8.38 \\
\hline Ptp.4069.1.A1_at & 574380 & AT3G54420.1 & ATEP3 (Arabidopsis thaliana chitinase class IV); chitinase & 2.43 & 5.50 & 7.72 \\
\hline PtpAffx.201130.1.S1_at & 549865 & AT1G17860.1 & $\begin{array}{l}\text { Trypsin and protease inhibitor family protein/Kunitz family } \\
\text { protein }\end{array}$ & 2.70 & 2.23 & 4.41 \\
\hline Ptp.5070.1.S1_s_at & 649729 & AT2G14610.1 & PR1 (pathogenesis-related gene 1) & 1.85 & 2.72 & 3.89 \\
\hline PtpAffx.1770.3.S1_s_at & 550049 & AT2G14580.1 & ATPRB1 (basic pathogenesis-related protein 1) & 2.31 & 2.57 & 3.61 \\
\hline \multicolumn{7}{|l|}{ Transport } \\
\hline PtpAffx.1235.1.A1_at & 573269 & AT4G35180.1 & LHT7 (lys/his transporter 7); amino acid permease & 3.34 & 4.88 & 8.59 \\
\hline PtpAffx.208208.1.S1_at & 431859 & AT5G46050.1 & ATPTR3/PTR3 (peptide transporter protein 3) & 3.22 & 1.68 & 4.99 \\
\hline PtpAffx.144197.2.A1_at & 708621 & AT1G15520.1 & $\begin{array}{l}\text { ATPDR12/PDR12 (pleiotropic drug resist. 12); ATPase, } \\
\text { transmembrane movement }\end{array}$ & 1.85 & 2.79 & 3.71 \\
\hline PtpAffx.217257.1.S1_at & 811670 & AT3G13080.1 & $\begin{array}{l}\text { ATMRP3 (multidrug resistance-associated protein 3); ABC } \\
\text { transporter }\end{array}$ & 2.14 & 3.67 & 3.73 \\
\hline
\end{tabular}


lowing the mixed infection. Overall, transcript levels for 618 probe sets were upregulated and 64 were downregulated by at least one of the three infection treatments relative to the control (Fig. 2B). Also, 92\% of the transcripts differentially regulated in response to $M$. larici-populina and $M$. medusae f. sp. deltoidae infections alone (Fig. 2A) were also differentially regulated by the mixed infection.

During annotation of the differentially expressed Affymetrix probe sets, we observed that a small fraction (approximately $1 \%$ ) displayed sequence similarity to proteins of fungal origin. In BLASTX searches against the GenBank nonredundant database, the best hits against these probe sets were fungal genes. For instance, the probe set PtpAffx.22193.1.S1_at is clearly a small subunit ribosomal protein of fungal origin $(E$ value $=7 \mathrm{E}$ 58), and the probe set PtpAffx.60650.1.S1_at corresponds to a fungal glutamine synthetase $(E$ value $=5 \mathrm{E}-22)$. For both of these, no hits were found against the Populus genome. These probe sets appear to have been designed from expressed sequence tag (EST) sequences derived from senescing leaves of field-grown $P$. tremula (Bhalerao et al. 2003) and most probably contained RNA from associated microorganisms such as endophytes or pathogenic fungi. Therefore, it should be kept in mind that the GeneChip Poplar Genome Array could contain some probe sets specific to ESTs that are not of poplar origin. These genes have been excluded from the statistical analyses.

\section{Particular changes following the mixed infection.}

A detailed analysis of the 648 transcripts differentially regulated in the mixed infection revealed that 266 genes showed less than a twofold expression difference relative to control when plants were infected solely with M. larici-populina or M. medusae f. sp. deltoidae. This set of 266 genes broke the threshold of a twofold change in the mixed infection (Supplementary Table $\mathrm{S} 1$ ). The remaining 382 probe sets in the mixed treatment are shared with $M$. larici-populina or M. medusae f. sp. deltoidae infections and were initially identified in separate M. larici-populina or M. medusae f. sp. deltoidae infections. Another 34 genes were differentially regulated in individual M. larici-populina or M. medusae f. sp. deltoidae treatments but not in the mixed treatment, for a total of 416 differentially regulated genes identified in individual responses (Fig. 2A).

A closer look at the 682 genes deregulated after at least one infection treatment revealed that 648 probe sets showed a greater response to the mixed infection than the response to individual infections. Then, the confirmation that the effect of the mixed infection is additive with respect to the single infections was done using the 648 deregulated probe sets with a $P$ value $<0.01$ in at least one treatment. It should be noted that the same density of inocula for each Melampsora spp. was used for the mixed infection, resulting in a doubling of the fungal inocula. We used this approach for the mixed infection so that we could directly compare the pattern of expression (respective fold-change for each treatment) of differentially regulated genes to determine whether the response toward one pathogen is influenced by the presence of the other. Our analysis of the mixed infection by comparison with singles infections revealed that all differentially regulated probe sets fit with the additive model in a two-way analysis of variance (ANOVA). This analysis suggests that, at the concentrations of inocula used in this study, the responses elicited by the two fungi interact minimally with one another.

\section{Functional classification of differentially regulated genes.}

All 682 genes differentially regulated in response to rust infection were annotated and classified into functional categories in accordance with the Munich Information Center for Protein Sequences (MIPS) Functional Catalogue (Ruepp et al. 2004), depending on the biological processes with which they are associated. Functional classification of the regulated genes was examined to decipher the molecular mechanisms underlying poplar defense responses and was grouped under four themes.

\section{Cell wall and secondary metabolism-related genes.}

Among cell-wall-modifying enzymes, probe sets encoding a putative cellulose synthase and a glucanase were upregulated in the mixed infections but an endoxyloglucan transferase was downregulated (Table 1). Furthermore, transcripts encoding a pectin methylesterase (PME) were also found induced (Table 1) but this corresponding PME probe set did not reach the twofold threshold in response to $M$. larici-populina or M. medusae f. sp. deltoidae infection. Several genes encoding enzymes of phenylpropanoid metabolism were differentially regulated in the mixed infection and almost cover the entire pathway (Fig. $3)$. Upregulated genes involved in lignin biosynthesis include phenylalanine ammonia lyase (PAL), cinnamate 4-hydroxylase $(\mathrm{C} 4 \mathrm{H})$, hydroxycinnamoyl transferase (HCT), 4-coumarate CoA ligase (4CL), caffeoyl-CoA 3-O-methyltransferase (CCoAOMT), cinnamoyl-CoA reductase (CCR), and cinnamyl alcohol dehydrogenase (CAD). Despite the lack of induction of chalcone synthase, which leads to the flavonoid pathway, some transcripts encoding enzymes of the flavonoid pathway, such as flavanone 3-hydroxylase-like protein and isoflavone reductase-like protein, were induced (Table 1). As well as genes involved with phenylpropanoid metabolism, we also found a transcript involved in terpene biosynthesis (terpene synthase/ cyclase) that was highly upregulated following the mixed infection.

\section{Signal perception and transduction during rust infection.}

Several genes involved in signal transduction mechanisms were differentially expressed after rust infection, such as receptor kinases, protein kinases, and calcium-mediated signal transduction proteins. For example, a transcript encoding a wall-associated kinase-like protein (WAKL) 2 was upregulated 16-fold in the mixed infection, and other members of this family were also induced (Table 1). A transcript encoding a putative systemin receptor was also induced in the mixed treatment. In addition, the Arabidopsis homolog receptor-like kinase (RLK)5 (protein ID. 202273) and genes encoding mitogenactivated protein kinase-kinase-kinase 5 (MAPKKK5) and calcium-dependent protein kinase were upregulated in the mixed infection. Finally, transcripts encoding proteins involved in calcium regulation were differentially regulated, such as a calcium-binding elongation factor-hand protein and an inositol phosphate synthase (Table 1).

With several induced transcripts encoding resistance (R) proteins, probe sets of this class were predominant in the signal perception mechanisms category. Some of these are members of the nucleotide binding site leucine-rich repeat (LRR) resistance genes (e.g., protein ID. 576722) (Table 1). Six genes related to the HR were also upregulated (Table 1). For instance, two different transcripts encoding products similar to the tobacco hypersensitive-response protein were highly induced (14and 10-fold in the mixed infection). Moreover, a transcript encoding a respiratory burst oxidative homolog (Rboh) similar to AtRbohF was also upregulated. Several transcripts encoding glutathione $S$-transferases (GST), which are involved in detoxification of toxic products triggered by the oxidative burst, were upregulated, including one that reached approximately 20-fold induction in the mixed infection (Table 1). In addition, a transcript encoding a putative elicitor-inducible cytochrome P450 (protein ID. 273420) was induced 15-fold in the mixed infection (Table 1) and could also play a role in detoxification during the infection process. 
An increase in transcript accumulation following rust infection was observed for many genes associated with hormone metabolism, such as genes encoding enzymes involved in the jasmonic acid biosynthesis pathway, including a lipooxygenase, an allene oxide synthase, and an allene oxide cyclase. Other transcripts encoding the 1-aminocyclopropane-1-carboxylate oxidase (ACC oxidase) and the 1-aminocyclopropane-1-carboxylate synthase (ACC synthase) that are involved in the ethylene biosynthesis pathway were induced in the mixed infection (Table 1).

We found several different probe sets corresponding to WRKY transcription factors that were differentially regulated in Melampsora spp.-infected leaves. The highest increase in transcript accumulation (more than 10-fold) was for homologs of Arabidopsis WRKY70, 51, and 40. We also found transcripts encoding AGAMOUS and EIL3 that were downregulated in the mixed infection. Members of other families of transcription factors were also up- or downregulated, including MYB, zinc-finger, bHLH, bZIP, and ethylene response factor (ERF) transcription factors.

\section{Deployment of antimicrobial effectors against rust pathogen.}

A considerable number of transcripts differentially regulated following rust infection encoded pathogenesis-related (PR) proteins, such as PR-1, PR-2 ( $\beta$-1,3-glucanase), PR-3 (acidic chitinase), PR-5 (thaumatin-like protein), and PR-8 (basic chitinase). High levels of induction were observed for these differentially regulated PR genes. For example, in the mixed infection, a $\beta$-1,3-glucanase was induced 16.5-fold, and a PR-1 and a PR-8 were also induced (3.9- and 8.4-fold, respectively). Three transcripts encoding Kunitz inhibitors were upregulated to 4.4-fold in the mixed infection. Moreover, AGD2-like defense response protein 1 (ALD1), which is an important gene in disease resistance and regulates PR-1 and camalexin production, showed high upregulation after $M$. medusae f. sp. deltoidae and mixed infection (Table 1).

A possible role for $\mathrm{ABC}$ transporters during rust infection.

Plant ABC transporters are membrane-localized protondriven efflux pumps that extrude toxic compounds from the cell. Genes encoding putative pleiotropic drug resistance (PDR)type $\mathrm{ABC}$ transporters and multidrug resistance-associated proteins (MRP)-type $\mathrm{ABC}$ transporters showed significant increases in transcript levels following rust infection (Table 1). A transcript encoding an Arabidopsis abc2 homologue was induced in the incompatible poplar-Melampsora spp. interaction described by Rinaldi and associates (2007). Previous studies have suggested that the involvement of PDR-type ABC transporters in plant resistance ensures traffic of defense-related metabolites (Eichhorn et al. 2006; Stukkens et al. 2005).

Validation of poplar GeneChip results by qPCR.

In order to validate the poplar GeneChip results, qPCR was performed on a set of eight selected genes of known function that were regulated by rust infection. Within this set of genes, six were upregulated and two were downregulated in the GeneChip analyses. We found a strong linear correlation $\left(R^{2}=0.92\right)$ between qPCR and GeneChip results (Fig. 4). Furthermore, the slope of the simple regression line was close to unity (0.94).

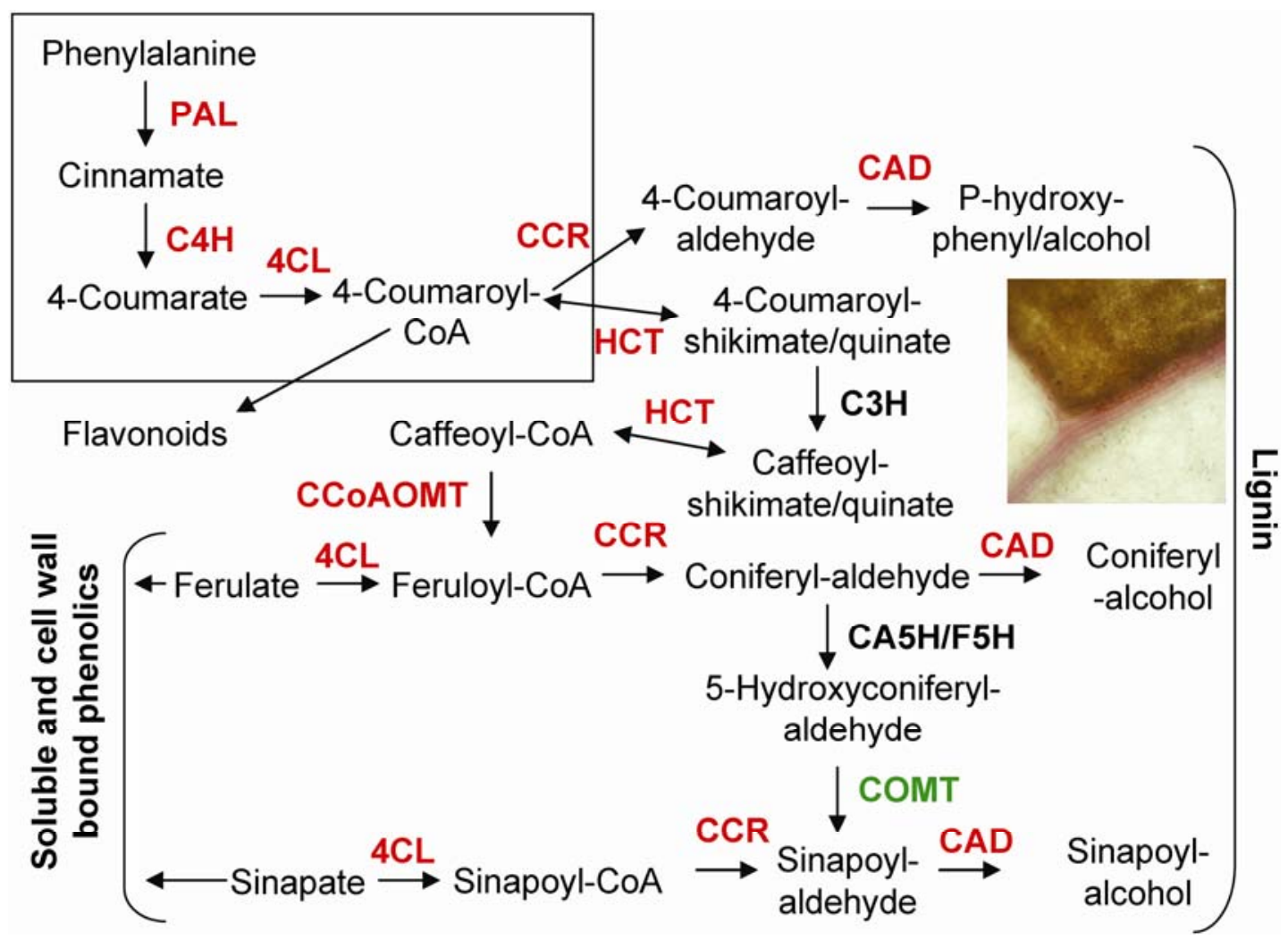

Fig. 3. Metabolic pathway related to phenylpropanoid metabolism. The box contains enzymes in the core phenylpropanoid pathway, an entry pathway for flavonoid, lignin, and soluble-phenolic biosynthesis. Arrows represent enzymatic reactions. Differentially regulated genes are colored green (downregulated) or red (upregulated) in response to the mixed infection. The figure is adapted from Hamberger and associates (2007). The photo on the right shows the detection of lignin compound after phloroglucinol staining 10 days after mixed infection. The corresponding protein ID from the poplar genome is shown in parentheses. PAL, phenylalanine ammonia lyase (770553 and 822571); C4H, cinnamate-4-hydroxylase (786206); HCT, hydroxycinnamoyl-CoA shikimate/quinate hydroxycinnamoyltransferase (835948); COMT, caffeic acid O-methyltransferase (552360); CCoAOMT, caffeoyl-CoA O-methyltransferase (829835); C3H, coumaroyl-shikimate 3'-hydroxylase (n.d.); F5H, coniferylaldehyde 5-hydroxylase (n.d.); 4CL, 4-coumarate-CoA ligase (639764); CCR, cinnamoyl-CoA reductase (421493); and CAD, cinnamyl alcohol dehydrogenase (549334). 
These results confirmed the high accuracy of the GeneChip Poplar Genome Array data. For example, transcripts encoding a $\beta$-1,3-glucanase (PR-2) and an NPR1 interactor (NRR) were upregulated to the same levels using both $\mathrm{qPCR}$ and GeneChip approaches. The expression patterns and putative functions of the eight genes selected to verify GeneChip data are shown in Supplementary Figure 1 and the primers used for qPCR validation are listed in Supplementary Table S3.

\section{DISCUSSION}

In this study, we analyzed the poplar transcriptome in response to leaf colonization with two biotrophic rust fungi, which exhibited contrasting phenotypes. We also investigated simultaneous infection with both fungal rusts to evaluate the potential interaction of the cellular response to Melampsora spp. infection. We found that the transcriptional response elicited by one pathogen is independent of the response to the other pathogen, which is in accordance with the absence of influence of the respective growth of each Melampsora sp. Analyses of differentially regulated transcripts in the mixed treatment showed that the two rust fungi operate quite independently of one another, and the effect of the double infection on the expression level of the identified genes is mostly additive.

\section{Distinct defense responses observed \\ following M. larici-populina and}

\section{M. medusae f. sp. deltoidae infection of poplar clone NM6.}

Following inoculation of the NM6 hybrid clone, M. laricipopulina colonized the host, whereas $M$. medusae f. sp. deltoidae showed limited development on the host and induced partial resistance accompanied by necroses. Analysis of fungal growth supports this observation at $6 \mathrm{dpi}$, because the compatible $M$. larici-populina strain showed over 250-fold increased growth while the partially incompatible $M$. medusae f. sp. deltoidae strain grew only 25 -fold. In a study by Rinaldi and associates (2007) that described the infection of $P$. trichocarpa $\times P$. deltoides "Beaupré" by compatible and incompatible strains of $M$. larici-populina, a 500-fold difference in fungal growth was observed at 4 dpi when the two strains were compared. The difference in fungal growth observed between Rinaldi and associates (2007) and our study is most probably due to the nature of the biological material used in the two studies. Rinaldi and associates (2007) examined qualitative resistance (incompatible interaction) whereas we examined quantitative resistance after $M$. medusae f. sp. deltoidae infection. In order to obtain a better overview of gene expression profiling after M. larici-populina and $M$. medusae f. sp. deltoidae infections, which should reflect our biological observations, we performed a genome-wide transcriptional analysis using the Affymetrix GeneChip array.

In the present study, we identified 276 poplar transcripts whose expression was altered following inoculation by a virulent pathogen (M. larici-populina) and 364 by a partially virulent pathogen (M. medusae f. sp. deltoidae) (Fig. 2A, Venn diagram). In recent transcriptomic studies of poplar-rust interactions, a larger number of genes were found differentially regulated by Melampsora spp. infection. For instance, Rinaldi and associates (2007) identified several more transcripts with altered expression after 2 dpi by an avirulent pathogen $(n=1,730)$ and a virulent pathogen $(n=280)$. Miranda and colleagues (2007) also found a high number of differentially regulated genes after inoculation with a virulent pathogen, with 1,388 array elements upregulated and 1,404 array elements downregulated. In this latter analysis, a time course with four timepoints $(1,3,6$, and 9 dpi) and a lower fold-change cutoff of 1.5 help explain the larger number of deregulated genes identified in the compatible interaction than Rinaldi and associates (2007). A careful comparison of responses after inoculation with virulent pathogens in our study (M. larici-populina) and that of Miranda and associates (2007) revealed 53 commonly differentially regulated genes, all of which overlapped with the 6- or 9-dpi timepoints. By contrast, only one gene overlapped with the 1-dpi timepoint and 15 with the 3-dpi timepoint. We also obtained a limited overlap of 49 genes between our $M$. larici-populina response and that of Rinaldi and associates (2007); however, only one gene (unknown function) was shared with the response to a virulent pathogen, whereas 48 genes were shared with the response to the avirulent pathogen. Thus, despite the similar numbers of genes differentially regulated after inoculation with virulent pathogens here $(n=276)$ and from Rinaldi and associates (2007) $(n=280)$, there is no common set of genes associated with these compatible interactions. We also compared genes differentially regulated after inoculation with the partially virulent $M$. medusae f. sp. deltoidae from our study with those from Miranda and associates (2007) and Rinaldi and associates (2007). We found 69 genes that overlapped with Miranda and associates (2007) and 55 genes that overlapped with Rinaldi and associates (2007). Most of the overlapping genes again occurred after 6 and 9 dpi (Miranda et al. 2007) or in the incompatible interaction (Rinaldi et al. 2007). Furthermore, many of these genes were also shared with our analysis of M. larici-populina infection. Therefore, we examined the functions of these genes, because they may have important roles in the poplar response against rust infection. Many encode proteins associated with signal transduction (calcium-binding proteins and putative LRR protein kinases), transcription (WRKY), stress response and detoxification (heat shock proteins and GST), and defense (disease-responsive and PR proteins), consistent with roles in signaling and subsequent plant defense. For example, homologs of Arabidopsis WRKY70 are shared in all three studies and this transcription factor is involved in pathogen defense of Arabidopsis (Knoth et al. 2007).

It is tempting to suggest that the larger overlap from Miranda and associates (2007) of responses after 6 and 9 dpi than 1 and 3 dpi is related to response kinetics; however, we note that Miranda and associates (2007) identified 3,336 differentially expressed array elements after 6 and 9 dpi but only 205 elements after 1 and 3 dpi. Also, the larger overlap from Rinaldi and associates (2007) of responses to avirulent than virulent pathogens correlates with the number of differentially expressed genes in each response (1,730 versus 280$)$. Thus, the overlap between the studies may not accurately reflect similarities in responses. Moreover, we note that the inherent bio-

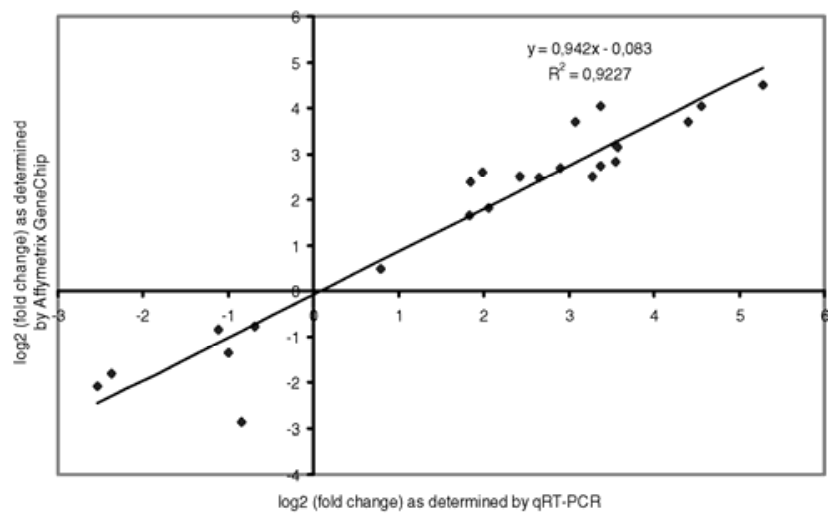

Fig. 4. Validation of GeneChip results using quantitative polymerase chain reaction (qPCR). $\log _{2}$ of fold change in Affymetrix GeneChip and qPCR are plotted for a subset of eight differentially expressed genes, and each is represented by three treatments (Melampsora larici-populina, M. medusae f. sp. deltoidae, and mixed infection). Data from qPCR represent the mean value obtained from three independent replicates; each was amplified two times. 
logical differences of the materials used in these studies should be considered, because various combinations of poplar genotypes versus Melampsora strains or species would be expected to result in specific lists of differentially regulated genes.

\section{An additive response in the mixed infection.}

Molecular studies of plant-microbe interactions often focus on the effect of a single pathogen on plant defense mechanisms and, thus, little is known about the combined effects of two or more simultaneous pathogen infections. Smith and associates (2004) analyzed the response of the poplar transcriptome to wounding and subsequent infection by a viral pathogen. They showed that the combination of wounding and viral infection had either additive or antagonistic effects on differentially regulated genes. The combination of various abiotic stresses has also been studied, such as the combined effect of drought and heat shock stresses on gene expression in Arabidopsis and tobacco (Rizhsky et al. 2002, 2004). Overall, these studies reveal complex interactions with a specific transcript profile signature for each combination of treatments.

Our results indicate that the response of poplar leaves to a mixed infection includes 266 transcripts (221 up- and 45 downregulated) that are specific to the combined infection and not found differentially expressed after individual $M$. laricipopulina or M. medusae f. sp. deltoidae treatments (Fig. 2B). However, detailed examination of the differentially regulated transcripts in the mixed treatment revealed an additive response for the large majority of these genes. Therefore, our analysis suggests that infection with $M$. medusae f. sp. deltoidae alone did not sufficiently induce these genes (above the twofold cutoff), and that infection with the virulent M. larici-populina contributed to the increase of the expression level above the twofold threshold in the mixed infection.

\section{Relationship between genes expressed in response to inoculation with virulent $M$. larici-populina and successful colonization of the host plant.}

Several transcripts that were differentially induced after $M$. larici-populina infection were associated with amino acid metabolism and transport, suggesting a possible mobilization and translocation of metabolites during interaction with biotrophs. We note that Rinaldi and associates (2007) did not find induction of metabolism-related genes in their study of a compatible interaction. This difference between the studies could be attributed to the short time frame ( $2 \mathrm{dpi})$ used for their analyses compared with ours (6 dpi). After successful invasion of the host, biotrophic pathogens develop haustoria within infected cells that serve as feeding organs or contribute to the establishment or maintenance of host compatibility (Mendgen et al. 2000; Voegele and Mendgen 2003). As described by Laurans and Pilate (1999), the development of haustoria structures occurs $17 \mathrm{~h}$ after infection in a compatible M. larici-populinapoplar interaction. We found several transcripts induced by the $M$. larici-populina infection that could be associated with the efficient penetration and growth of the virulent pathogen in the plant host. For example, a transcript encoding a PR gene with similarity to blight-associated protein p12 (protein ID. 819386) was highly induced in the compatible interaction (15-fold). This gene also shares similarity with an Arabidopsis thaliana expansin (Kayim et al. 2004), which is associated with cell wall loosening and may allow efficient penetration of the invading pathogen. Furthermore, the increase in invertase expression (which converts sucrose into glucose and fructose) could also be viewed as part of fungal pathogenesis because fungi use glucose rather than sucrose (Sturm and Tang 1999). Increased invertase activity has been reported for a number of biotrophic interactions (Fotopoulos et al. 2003; Swarbrick et al. 2006).
M. larici-populina and $M$. medusae f. sp. deltoidae infections affect regulation of a shared set of genes.

According to previous studies, expression profiles corresponding to different types of interactions with pathogens (e.g., compatible versus incompatible) are often quite similar (Katagiri 2004; Nimchuk et al. 2003), and several examples are reported where a large percentage of genes have altered transcript levels in response to pathogen infection (Tao et al. 2003). Transcripts that were regulated in response to both $M$. larici-populina and $M$. medusae f. sp. deltoidae infections (Fig. 2A, intersection) represented approximately 54\% of the 416 rust-response genes, and are also largely included in the mixed infection (Fig. 2B, intersection of all infections). Such a high percentage was also reported for an interaction between tomato and a biotrophic powdery mildew fungus, where $42 \%$ of the regulated genes were found in both compatible and incompatible interactions ( $\mathrm{Li}$ et al. 2006). Furthermore, Tao and associates (2003) identified a group of defense-related genes shared in both the compatible and incompatible interactions involving Arabidopsis and the bacterial pathogen Pseudomonas syringae. They concluded that several molecular mechanisms are shared by the two host-pathogen interactions.

\section{From fungal recognition to defense responses.}

Plant recognition of pathogens is mediated by proteins such as RLKs, which represent one of the major receptor systems for intercellular signaling pathways in plants. RLKs perceive external signals at the plasma membrane and initiate signaling cascades via their cytoplasmic protein kinase domains (Nürnberger and Kernmerling 2006). We found several differentially regulated transcripts encoding RLKs, including a WAKL similar to Arabidopsis WAKL2. Differentially regulated genes encoding LRR receptors such as a systemin-like receptor and a bacterial blight resistance protein Xa26 from rice were also identified. In the context of a gene-for-gene defense response, the resistance-avirulence interactions trigger the HR from the host, resulting in localized cell death (Belkhadir et al. 2004). Interestingly, we found that several HR-related genes were upregulated in the M. medusae f. sp. deltoidae infection, suggesting that the quantitative resistance described in this study induces defense responses that overlap with qualitative resistance. The Rboh gene family has been reported to be transcriptionally upregulated by pathogens or fungal elicitors (Torres and Dangl 2005). Consequently, the identification of an Rboh poplar homolog in our study also supports the establishment of an HR-like response. Furthermore, we also identified several transcripts encoding enzymes such as GST that may protect cells from an oxidative burst.

As expected for the defense response against biotrophic pathogens, many PR genes that are normally involved in the salicylic acid (SA)-dependent pathways (Glazebrook 2005), such as chitinase and PR-1, were induced following Melampsora spp. infection. Nevertheless, genes involved in jasmonic acid (JA) and ethylene signaling were also clearly activated after Melampsora spp. infection, because almost all the genes encoding enzymes of JA and ethylene pathways were induced. It remains unclear whether JA and ethylene signaling play important roles during poplar rust infection, or whether this hormonal shift results from poplar leaf colonization and the resulting localized response (defense response and necroses). Consistent with our observations, a previous study of Arabidopsis (Ellis et al. 2002) suggested that JA signaling enhances resistance to the biotrophic fungus Golovinomyces cichoracearum. In addition, Chen and associates (2003) showed an increased production of ethylene during the biotrophic phase of Colletotrichum destructivum infection on Nicotiana tabacum. Following the trigger of the defense response, several tran- 
scriptional regulators such as WRKY members were identified to play a major role in the regulation of defense responses (Eulgem 2006). Here, eight different orthologs of Arabidopsis WRKY transcription factors were shown differentially expressed following rust infection and the majority of these, such as WRKY70, are clearly associated with defense response (Knoth et al. 2007; Li et al. 2004).

A consequence of plant basal defense against pathogens is the modification of the plant cell wall, which provides an important barrier against pathogen penetration (Hückelhoven 2007). Cellulose synthase-like enzymes were upregulated in our study and a xyloglucan endotransglycosylase (XET) was downregulated. XET are cell wall disassembly enzymes that alter carbohydrate linkages and recent studies have shown that XET are repressed upon pathogen infection (Ditt et al. 2006; Ithal et al. 2007). Moreover, many lignin biosynthesis genes were upregulated in the mixed infection, suggesting that poplar leaves respond to pathogen invasion by lignin deposition to strengthen the cell wall (Fig. 3). However, no major trends were observed between virulent (M. larici-populina) and partially virulent (M. medusae f. sp. deltoidae) pathogens for lignin biosynthesis genes. For instance, close analysis of the ligninrelated transcripts revealed that only the CAD-encoding probe set showed a clear fold change in both treatments.

Last, we also found upregulation of some Kunitz trypsin inhibitors (TI) by rust infection. Kunitz TI are a family of protease inhibitors that are often induced by wounding and herbivory in trembling aspen and hybrid poplar (Christopher et al. 2004; Haruta et al. 2001). A study of potato reported the induction of Kunitz inhibitors after infection with Phytophthora infestans or P. sojae (Valueva et al. 1998); however, studies of the role of Kunitz inhibitors in fungi-induced defense are scarce. Miranda and associates (2007) showed an induction of Kunitz TI early ( $1 \mathrm{dpi}$ ) in a compatible interaction involving poplar and M. medusae but repression of the transcripts occurred later in the infection process $(3,6$, and $9 \mathrm{dpi})$. In contrast, we found upregulation of Kunitz TI against Melampsora spp. at $6 \mathrm{dpi}$, indicating that this induction is not due to the effect of wounding due to leaf excision but rather to fungal colonization. A close analysis of the phylogeny of the Kunitz TI family from the Populus trichocarpa genome (Major and Constabel 2008) revealed that the upregulated Kunitz TI in the present work belong to group $\mathrm{C}$, which contains members that are not induced by wounding or insect attack. This group of Kunitz TI is probably involved in defense against fungi.

Overall, our results showed an additive response of the two fungi in the mixed infection, which confirms that the poplar clone NM6 responds independently to each pathogen, as was demonstrated by growth profiles. This transcriptome analysis of the poplar-rust interaction clearly highlights potential key genes that determine the outcome of this biotrophic interaction. However, we are cautious in our interpretation of the data because a large number of genes are shared in both virulent and less-virulent interactions and the time course of gene induction is an important issue that has a strong impact on pathogen growth. Nevertheless, more detailed analyses of potential genes should shed some light on their role in virulence or resistance.

\section{MATERIALS AND METHODS}

\section{Plant material, growth conditions, and Melampsora spp. infections.}

Poplar clone NM6 (P. nigra $\times P$. maximowiczii) was grown in Promix soil under controlled greenhouse conditions prior to inoculation. NM6 plants were kept under a 16-h photoperiod with weekly fertilizations (20:20:20, N:P:K). Fully expanded leaves from leaf plastochron index (LPI) five and six were de- tached from four individual NM6 plants for inoculations. $M$. larici-populina and M. medusae f. sp. deltoidae were maintained on clone Jackii $(P$. balsamifera L. $\times P$. deltoides Marsh.). Four half-leaves from LPI5 and LPI6 were sampled randomly in 22.5-by-22.5-cm petri dishes and were inoculated on their abaxial side with $M$. larici-populina, M. medusae f. sp. deltoidae, or a mixture of them at a density of 2,000 urediospores $/ \mathrm{cm}^{2}$ in $0.01 \%$ Tween as described previously (Boyle et al. 2005). We specify that in the mixed infection we inoculated 2,000 urediospores $/ \mathrm{cm}^{2}$ of each pathogen. Mock infected leaves were sprayed with $0.01 \%$ Tween only. The inoculated leaves, as well as mock-infected leaves, were kept on wet paper inside the parafilm-sealed petri dishes and were incubated in a growth chamber at $18^{\circ} \mathrm{C}$ with a 16 -h photoperiod. At 6 dpi, each half-leaf corresponding to a biological replication was ground into powder in liquid nitrogen and frozen immediately for RNA and DNA isolation. For GeneChip analysis, we kept only three replicates per infection.

\section{DNA and RNA isolation.}

DNA and RNA were extracted from frozen leaf tissues using the DNeasy system and the RNAeasy plant mini kit (Qiagen, Mississauga, ON, Canada) according to the manufacturer's instructions. Total RNA extraction was performed with Qiagen from $100 \mathrm{mg}$ of frozen material. Following a DNase I treatment (Qiagen), $10 \mu \mathrm{g}$ of total RNA from each biological sample was used for each microarray experiment. RNA samples were analyzed on Bioanalyzer 2100 (Agilent Technologies, Inc., Santa Clara, CA, U.S.A.) prior to GeneChip hybridization.

\section{Expression analysis} using GeneChip Poplar Genome Array.

The GeneChip Poplar Genome Array (Affymetrix, Santa Clara, CA, U.S.A.) contains 61,414 probe sets representing over 56,000 transcripts and predicted genes. In all, 12 arrays were used in this study, which correspond to 12 RNA samples from three biological replicates each of four treatments: three Melampsora spp. infections (M. larici-populina alone, $M$. medusae f. sp. deltoidae alone, and M. larici-populina and M. medusae f. sp. deltoidae simultaneously) and one mock control. To assess this interaction, each fungus was applied at the same density in the mixed as in the corresponding single-fungus infection.

RNA quality assessment, cRNA preparation, labeling, hybridization, and data acquisition of Affymetrix poplar GeneChips were performed by the Functional Genomics Platform at the Genome Quebec Innovation Centre at McGill University (Montreal, QC, Canada). Data and statistical analyses for identification of differentially regulated genes were performed using FlexArray, a software package developed by M. Blazejczyk and associates (Genome Quebec, Montreal) that uses R and BioConductor (Gentleman et al. 2004) and provides an easy-touse interface that facilitates signal processing, data visualization, and statistical analysis. The raw data were adjusted for background signal and normalized across all GeneChips using the Robust Multi-array Average (RMA) method (Irizarry et al. 2003). To identify differentially expressed genes, a SAM was performed using the "siggenes" package of Bioconductor through FlexArray (Tusher et al. 2001). SAM minimizes the coefficient of variation across arrays and incorporates an estimate of false discovery rate (FDR) (Benjamini and Hochberg 1995). For any particular comparison, only genes with a $P$ value $\leq 0.01$ and a fold change $>2$ (or $<0.5$ ) were considered to be up- or downregulated. All materials and procedures comply with the MIAME standards set for array data (Brazma et al. 2001). The full data set has been deposited in the Gene Expression Omnibus (GEO) and is accessible through GEO Series accession number GSE9673. 
We used the Affymetrix NetAffix analysis center, the Joint Genome Institute poplar genome database query, and BLAST similarity searches to annotate candidate genes. Annotations were done using the Arabidopsis Information Resource (TAIR) genome annotation, version 8 . Each gene was assigned to a functional class using the MIPS classification scheme (Ruepp et al. 2004). A recent database, PopARRAY, allowing crossreferencing of Affymetrix and Nimblegen microarray platforms in Populus spp., was used to compare our results with those of Rinaldi and associates (2007).

All probe sets identified in the SAM analysis were investigated for additive gene expression patterns. The average control expression $\left(\log _{2}\right)$ was removed from the expression values of each infection to specifically analyze the portion of gene expression resulting from the presence of pathogens. Therefore, expected additive values are defined as $\log _{2} M$. larici-populina + $\log _{2} M$. medusae f. sp. deltoidae in a two-way ANOVA analysis, where $\log _{2}$ mixed is the dependent variable. Values outside the $99 \%$ confidence level did not fit the additive model and were considered nonadditive.

\section{qPCR analysis.}

Pathogen growth was quantified according to the increase in pathogen DNA mass measured by qPCR between day 0 and day 6 as described previously (Boyle et al. 2005). Amplifications were performed using an Opticon2 DNA Engine (MJ Research, Waltham, MA, U.S.A.) and $1 \times$ QuantiTect SYBR Green mixture (Qiagen). Oligonucleotides were used at a concentration of $0.25 \mu \mathrm{M}$ and primer sequences are provided in Supplementary Table S2. All experiments were done in triplicate and each replication was repeated two times.

Eight differentially expressed genes identified from the GeneChip analysis were selected to validate the results by qPCR. Quantification was done as described earlier using a cDNA template prepared from the same RNA samples used for GeneChip analysis. A set of eight differentially expressed genes (six up- and two downregulated genes) were selected for qPCR validation. Standard deviation values were calculated from $\log _{2}$-transformed data. We previously identified $C d c 2$ as a constitutively expressed gene (Nicole et al. 2006) and, therefore, used this as an internal control for normalization of the results in qPCR analysis.

\section{ACKNOWLEDGMENTS}

A. Azaiez is the recipient of a postdoctoral Visiting Fellowship in Canadian Government Laboratories from the Natural Sciences and Engineering Research Council of Canada. We thank I. Major and M.-J. Morency for critical review and scientific comments on the manuscript, M. BernierCardou for statistical advice, A. Tremblay for qPCR analyses to validate GeneChip data, P. Cheers for editing work, and the knowledgeable reviewers for their constructive criticism of an earlier version of this article.

\section{LITERATURE CITED}

Belkhadir, Y., Subramaniam, R., and Dangl, J. L. 2004. Plant disease resistance protein signaling: NBS-LRR proteins and their partners. Curr. Opin. Plant Biol. 7:391-399.

Benjamini, Y., and Hochberg, Y. 1995. Controlling the false discovery rate: A practical and powerful approach to multiple testing. J. R. Stat. Soc. B. 57:289-300

Bhalerao, R. P., Keskitalo, J., Sterky, F., Erlandsson, R., Bjorkbacka, H., Birve, S. J., Karlsson, J., Gardestrom, P., Gustafsson, P., Lundeberg, J., and Jansson, S. 2003. Gene expression in autumn leaves. Plant Physiol. 131:430-442.

Bittel, P., and Robatzek, S. 2007. Microbe-associated molecular patterns (MAMPs) probe plant immunity. Curr. Opin. Plant Biol. 10:335-341.

Boyle, B., Hamelin, R. C., and Séguin, A. 2005. In vivo monitoring of obligate biotrophic pathogen growth by kinetic PCR. Appl. Environ. Microbiol. 71:1546-1552.
Brazma, A., Hingamp, P., Quackenbush, J., Sherlock, G., Spellman, P., Stoeckert, C., Aach, J., Ansorge, W., Ball, C. A., Causton, H. C., Gaasterland, T., Glenisson, P., Holstege, F. C. P., Kim, I. F., Markowitz, V., Matese, J. C., Parkinson, H., Robinson, A., Sarkans, U., SchulzeKremer, S., Stewart, J., Taylor, R., Vilo, J., and Vingron, M. 2001. Minimum information about a microarray experiment (MIAME) - toward standards for microarray data. Nat. Genet. 29:365-371.

Brunner, A. M., Busov, V. B., and Strauss, S. H. 2004. Poplar genome sequence: Functional genomics in an ecologically dominant plant species. Trends Plant Sci. 9:49-56.

Caldo, R. A., Nettleton, D., Peng, J. Q., and Wise, R. P. 2006. Stagespecific suppression of basal defense discriminates barley plants containing fast- and delayed-acting Mla powdery mildew resistance alleles. Mol. Plant-Microbe Interact. 19:939-947.

Chen, N., Goodwin, P. H., and Hsiang, T. 2003. The role of ethylene during the infection of Nicotiana tabacum by Colletotrichum destructivum. J. Exp. Bot. 54:2449-2456.

Christopher, M. E., Miranda, M., Major, I. T., and Constabel, C. P. 2004 Gene expression profiling of systemically wound-induced defenses in hybrid poplar. Planta 219:936-947.

Clarke, J. D., and Zhu, T. 2006. Microarray analysis of the transcriptome as a stepping stone towards understanding biological systems: Practical considerations and perspectives. Plant J. 45:630-650.

Ditt, F. R., Kerr, F. K., de Figueiredo, P., Delrow, J., Comai, L., and Nester, W. E. 2006. The Arabidopsis thaliana transcriptome in response to Agrobacterium tumefaciens. Mol. Plant-Microbe Interact. 19:665-681.

Eichhorn, H., Klinghammer, M., Becht, P., and Tenhaken, R. 2006. Isolation of a novel $\mathrm{ABC}$-transporter gene from soybean induced by salicylic acid. J. Exp. Bot. 57:2193-2201.

Ellis, C., Karafyllidis, I., and Turner, J. G. 2002. Constitutive activation of jasmonate signaling in an Arabidopsis mutant correlates with enhanced resistance to Erysiphe cichoracearum, Pseudomonas syringae, and Myzus persicae. Mol. Plant-Microbe Interact. 15:1025-1030.

Eulgem, T. 2005. Regulation of the Arabidopsis defense transcriptome. Trends Plant Sci. 10:71-78.

Eulgem, T. 2006. Dissecting the $W R K Y$ web of plant defense regulators. PLoS Pathog. 2:e126.

Fotopoulos, V., Gilbert, M. J., Pittman, J. K., Marvier, A. C., Buchanan, A. J., Sauer, N., Hall, J. L., and Williams, L. E. 2003. The monosaccharide transporter gene, AtSTP4, and the cell-wall invertase, Atßfructl, are induced in Arabidopsis during infection with the fungal biotroph Erysiphe cichoracearum. Plant Physiol. 132:821-829.

Fung, R. W. M., Gonzalo, M., Fekete, C., Kovacs, L. G., He, Y., Marsh, E., McIntyre, L. M., Schachtman, D. P., and Qiu, W. 2008. Powdery mildew induces defense-oriented reprogramming of the transcriptome in a susceptible but not in a resistant grapevine. Plant Physiol. 146:236-249.

Garcia-Brugger, A., Lamotte, O., Vandelle, E., Bourque, S., Lecourieux, D., Poinssot, B., Wendehenne, D., and Pugin, A. 2006. Early signaling events induced by elicitors of plant defenses. Mol. Plant-Microbe Interact. 19:711-724.

Gentleman, R., Carey, V., Bates, D., Bolstad, B. , Dettling, M., Dudoit, S., Ellis, B., Gautier, L., Ge, Y., Gentry, J., Hornik, K., Hothorn, T., Huber, W., Iacus, S., Irizarry, R., Leisch, F., Li, C., Maechler, M., Rossini, A., Sawitzki, G., Smith, C. , Smyth, G., Tierney, L., Yang, J., and Zhang, J. 2004. Bioconductor: Open software development for computational biology and bioinformatics. Genome Biol. 5:R80.

Gérard, P. R., Husson, C., Pinon, J., and Frey, P. 2006. Comparison of genetic and virulence diversity of Melampsora larici-populina populations on wild and cultivated poplar and influence of the alternate host. Phytopathology 96:1027-1036.

Glazebrook, J. 2005. Contrasting mechanisms of defense against biotrophic and necrotrophic pathogens. Annu. Rev. Phytopathol. 43:205-227.

Hamberger, B., Ellis, M., Friedmann, M., de Azevedo Souza, C., Barbazuk, B., and Douglas, C. J. 2007. Genome-wide analyses of phenylpropanoidrelated genes in Populus trichocarpa, Arabidopsis thaliana, and Oryza sativa: The Populus lignin toolbox and conservation and diversification of angiosperm gene families. Can. J. Bot. 85:1182-1201.

Haruta, M., Major, I. T., Christopher, M. E., Patton, J. J., and Constabel, C. P. 2001. A Kunitz trypsin inhibitor gene family from trembling aspen (Populus tremuloides Michx.): Cloning, functional expression, and induction by wounding and herbivory. Plant Mol. Biol. 46:347-359.

Hückelhoven, R. 2007. Cell wall-associated mechanisms of disease resistance and susceptibility. Annu. Rev. Phytopathol. 45:101-127.

Irizarry, R. A., Bolstad, B. M., Collin, F., Cope, L. M., Hobbs, B., and Speed, T. P. 2003. Summaries of Affymetrix GeneChip probe level data. Nucleic Acids Res. 31:e15.

Ithal, N., Recknor, J., Nettleton, D., Hearne, L., Maier, T., Baum, T. J., and Mitchum, M. G. 2007. Parallel genome-wide expression profiling of host and pathogen during soybean cyst nematode infection of soybean. Mol. Plant-Microbe Interact. 20:293-305. 
Jones, J. D. G., and Dangl, J. L. 2006. The plant immune system. Nature 444:323-329.

Katagiri, F. 2004. A global view of defense gene expression regulation-A highly interconnected signaling network. Curr. Opin. Plant Biol. 7:506511.

Kayim, M., Ceccardi, T. L., Berretta, M. J. G., Barthe, G. A., and Derrick, K. S. 2004. Introduction of a citrus blight-associated gene into Carrizo citrange [Citrus sinensis (L.) Osbc. $\times$ Poncirus trifoliata (L.) Raf.] by Agrobacterium-mediated transformation. Plant Cell Rep. 23:377-385.

Knoth, C., Ringler, J., Dangl, J. L., and Eulgem, T. 2007. Arabidopsis WRKY70 is required for full RPP4-mediated disease resistance and basal defense against Hyaloperonospora parasitica. Mol. PlantMicrobe Interact. 20:120-128.

Laurans, E., and Pilate, G. 1999. Histological aspects of a hypersensitive response in poplar to Melampsora larici-populina. Phytopathology 89:233-238.

Li, C., Bai, Y., Jacobsen, E., Visser, R., Lindhout, P., and Bonnema, G. 2006. Tomato defense to the powdery mildew fungus: Differences in expression of genes in susceptible, monogenic- and polygenic resistance responses are mainly in timing. Plant Mol. Biol. 62:127-140.

Li, J., Brader, G., and Palva, E. T. 2004. The WRKY70 transcription factor: A node of convergence for jasmonate-mediated and salicylate-mediated signals in plant defense. Plant Cell 16:319-331.

Major, I. T., and Constabel, C. P. 2006. Molecular analysis of poplar defense against herbivory: Comparison of wound- and insect elicitorinduced gene expression. New Phytol. 172:617-635.

Major, I. T., and Constabel, C. P. Functional analysis of the Kunitz trypsin inhibitor family in poplar reveals biochemical diversity and multiplicity in defense against herbivores. Plant Physiol. 146:888-903.

Mendgen, K., Struck, C., Voegele, R. T., and Hahn, M. 2000. Biotrophy and rust haustoria. Physiol. Mol. Plant Pathol. 56:141-145.

Miranda, M., Ralph, S. G., Mellway, R., White, R., Heath, M. C., Bohlmann, J., and Constabel, C. P. 2007. The transcriptional response of hybrid poplar (Populus trichocarpa $\times$ P. deltoides) to infection by Melampsora medusae leaf rust involves induction of flavonoid pathway genes leading to the accumulation of proanthocyanidins. Mol. PlantMicrobe Interact. 20:816-831.

Newcombe, G. 1996. The specificity of fungal pathogens on Populus. Pages 223-246 in: Biology of Populus and its Implications for Management and Conservation. R. F. Stettler, H. D. Bradshaw, Jr., P. E. Heilman, and T. M. Hinckley, eds. NRC Research Press, Ottawa, ON, Canada.

Nicole, M.-C., Hamel, L.-P., Morency, M.-J., Beaudoin, N., Ellis, B. E., and Séguin, A. 2006. MAP-ping genomic organization and organ-specific expression profiles of poplar MAP kinases and MAP kinase kinases. BMC Genomics 7:223

Nimchuk, Z., Eulgem, T., Holt, B. F., and Dangl, J. L. 2003. Recognition and response in the plant immune system. Annu. Rev. Genet. 37:579-609.

Nürnberger, T., and Kernmerling, B. 2006. Receptor protein kinases-pattern recognition receptors in plant immunity. Trends Plant Sci. 11:519522

Panthee, D., Yuan, J., Wright, D., Marois, J., Mailhot, D., and Stewart, C. 2007. Gene expression analysis in soybean in response to the causal agent of Asian soybean rust (Phakopsora pachyrhizi Sydow) in an early growth stage. Funct. Integr. Genomics 7:291-301.

Prakash, S. H., and Heather, W. A. 1986. Inheritance of resistance to races of Melampsora medusae in Populus deltoides. Silvae Genet. 35:74-77.

Ralph, S., Oddy, C., Cooper, D., Yueh, H., Jancsik, S., Kolosova, N., Philippe, R. N., Aeschliman, D., White, R., Huber, D., Ritland, C. E., Benoit, F., Rigby, T., Nantel, A., Butterfield, Y. S. N., Kirkpatrick, R., Chun, E., Liu, J., Palmquist, D., Wynhoven, B., Stott, J., Yang, G., Barber, S., Holt, R. A., Siddiqui, A., Jones, S. J. M., Marra, M. A., Ellis, B. E., Douglas, C.J., Ritland, K., and Bohlmann, J. 2006. Genomics of hybrid poplar (Populus trichocarpa $\times$ deltoides) interacting with forest tent caterpillars (Malacosoma disstria): Normalized and full-length cDNA libraries, expressed sequence tags, and a cDNA microarray for the study of insect-induced defences in poplar. Mol. Ecol. 15:1275-1297.

Ramonell, K. M., and Somerville, S. 2002. The genomics parade of defense responses: To infinity and beyond. Curr. Opin. Plant Biol. 5:291-294.

Rinaldi, C., Kohler, A., Frey, P., Duchaussoy, F., Ningre, N., Couloux, A., Wincker, P., Le Thiec, D., Fluch, S., Martin, F., and Duplessis, S. 2007. Transcript profiling of poplar leaves upon infection with compatible and incompatible strains of the foliar rust Melampsora larici-populina. Plant Physiol. 144:347-366.

Rizhsky, L., Liang, H., and Mittler, R. 2002. The combined effect of drought stress and heat shock on gene expression in tobacco. Plant Physiol. 130:1143-1151.
Rizhsky, L., Liang, H., Shuman, J., Shulaev, V., Davletova, S., and Mittler, R. 2004. When defense pathways collide. The response of Arabidopsis to a combination of drought and heat stress. Plant Physiol. 134:1683-1696.

Ruepp, A., Zollner, A., Maier, D., Albermann, K., Hani, J., Mokrejs, M., Tetko, I., Guldener, U., Mannhaupt, G., Munsterkotter, M., and Mewes, H. W. 2004. The FunCat, a functional annotation scheme for systematic classification of proteins from whole genomes. Nucleic Acids Res. 32:5539-5545

Smith, C. M., Rodriguez-Buey, M., Karlsson, J., and Campbell, M. M. 2004. The response of the poplar transcriptome to wounding and subsequent infection by a viral pathogen. New Phytol. 164:123-136.

Stukkens, Y., Bultreys, A., Grec, S., Trombik, T., Vanham, D., and Boutry, M. 2005. NpPDR1, a pleiotropic drug resistance-type ATP-binding cassette transporter from Nicotiana plumbaginifolia, plays a major role in plant pathogen defense. Plant Physiol. 139:341-352.

Sturm, A., and Tang, G. Q. 1999. The sucrose-cleaving enzymes of plants are crucial for development, growth and carbon partitioning. Trends Plant Sci. 4:401-407.

Swarbrick, P. J., Schulze-Lefert, P., and Scholes, J. D. 2006. Metabolic consequences of susceptibility and resistance (race-specific and broadspectrum) in barley leaves challenged with powdery mildew. Plant Cell Environ. 29:1061-1076.

Tao, Y., Xie, Z., Chen, W., Glazebrook, J., Chang, H.-S., Han, B., Zhu, T., Zou, G., and Katagiri, F. 2003. Quantitative nature of Arabidopsis responses during compatible and incompatible interactions with the bacterial pathogen Pseudomonas syringae. Plant Cell 15:317-330.

Torres, M. A., and Dangl, J. L. 2005. Functions of the respiratory burst oxidase in biotic interactions, abiotic stress and development. Curr. Opin. Plant Biol. 8:397-403.

Tusher, V. G., Tibshirani, R., and Chu, G. 2001. Significance analysis of microarrays applied to the ionizing radiation response. Proc. Natl. Acad. Sci. U.S.A. 98:5116-5121.

Tuskan, G. A., DiFazio, S., Jansson, S., Bohlmann, J., Grigoriev, I., Hellsten, U., Putnam, N., Ralph, S., Rombauts, S., Salamov, A., Schein, J., Sterck, L., Aerts, A., Bhalerao, R. R., Bhalerao, R. P., Blaudez, D., Boerjan, W., Brun, A., Brunner, A., Busov, V., Campbell, M., Carlson, J., Chalot, M., Chapman, J., Chen, G. L., Cooper, D., Coutinho, P. M., Couturier, J., Covert, S., Cronk, Q., Cunningham, R., Davis, J., Degroeve, S., Dejardin, A., dePamphilis, C., Detter, J., Dirks, B., Dubchak, I., Duplessis, S., Ehlting, J., Ellis, B., Gendler, K., Goodstein, D., Gribskov, M., Grimwood, J., Groover, A., Gunter, L., Hamberger, B., Heinze, B., Helariutta, Y., Henrissat, B., Holligan, D., Holt, R., Huang, W., IslamFaridi, N., Jones, S., Jones-Rhoades, M., Jorgensen, R., Joshi, C., Kangasjarvi, J., Karlsson, J., Kelleher, C., Kirkpatrick, R., Kirst, M., Kohler, A., Kalluri, U., Larimer, F., Leebens-Mack, J., Leple, J. C., Locascio, P., Lou, Y., Lucas, S., Martin, F., Montanini, B., Napoli, C., Nelson, D. R., Nelson, C., Nieminen, K., Nilsson, O., Pereda, V., Peter, G., Philippe, R., Pilate, G., Poliakov, A., Razumovskaya, J., Richardson, P., Rinaldi, C., Ritland, K., Rouze, P., Ryaboy, D., Schmutz, J., Schrader, J., Segerman, B., Shin, H., Siddiqui, A., Sterky, F., Terry, A., Tsai, C. J., Uberbacher, E., Unneberg, P., Vahala, J., Wall, K., Wessler, S., Yang, G., Yin, T., Douglas, C., Marra, M., Sandberg, G., Van de Peer, Y., and Rokhsar, D. 2006. The genome of black cottonwood, Populus trichocarpa (Torr. \& Gray). Science 313:1596-1604.

Valueva, T. A., Revina, T. A., Kladnitskaya, G. V., and Mosolov, V. V. 1998. Kunitz-type proteinase inhibitors from intact and Phytophthora-infected potato tubers. FEBS (Fed. Cur. Biochem. Soc.) Lett. 426:131-134.

Voegele, R. T., and Mendgen, K. 2003. Rust haustoria: Nutrient uptake and beyond. New Phytol. 159:93-100.

Wise, R. P., Moscou, M. J., Bogdanove, A. J., and Whitham, S. A. 2007. Transcript profiling in host-pathogen interactions. Annu. Rev. Phytopathol. 45:329-369.

\section{AUTHOR-RECOMMENDED INTERNET RESOURCES}

Affymetrix NetAffix analysis center: www.affymetrix.com/analysis/index.affx

FlexArray software: genomequebec.mcgill.ca/FlexArray

Joint Genome Institute poplar genome database query: genome.jgi-psf.org

Munich Information Center for Protein Sequences (MIPS) classification website: mips.gsf.de/proj/funcatDB

PopARRAY website: popgenome.ag.utk.edu/mdb

The National Center for Biotechnology Information (NCBI) Gene Expression Omnibus website: www.ncbi.nlm.nih.gov/geo

The NCBI BLAST search website: www.ncbi.nlm.nih.gov/BLAST

The R project website: www.r-project.org 